\title{
Process Optimization of Automotive Brake Material in Dry Sliding using Taguchi and ANOVA Techniques for Wear Control
}

\section{Ashish Saurabh}

BITS Pilani - Hyderabad Campus

Kartik Joshi

BITS Pilani - Hyderabad Campus

Manoj Abhinav

BITS Pilani - Hyderabad Campus

Piyush Chandra Verma ( $\sim$ piyushchandraverma@hyderabad.bits-pilani.ac.in )

BITS Pilani - Hyderabad Campus

\section{Research Article}

Keywords: Semi-metallic Brake Pad, Taguchi, ANOVA, Wear Control, MINITAB, Process optimization.

Posted Date: March 3rd, 2022

DOI: https://doi.org/10.21203/rs.3.rs-1391284/v1

License: (a) (i) This work is licensed under a Creative Commons Attribution 4.0 International License. Read Full License 


\section{Abstract}

Semi-metallic brake pads are more durable, fade-resistant, and long-lasting; thus, their tribological qualities are further studied. Taguchi's experimental technique is crucial for determining the impact of various braking limitations on semi-metallic brake pad performance. Taguchi's approach was utilized to create an experimental design using an L9 orthogonal array to examine the output. The effect of multiple parameter interactions and the relative contributions of each studied control is determined using ANOVA. At room temperature and humidity, tests were done under dry sliding circumstances with changing sliding velocity $(1.047 \mathrm{~m} / \mathrm{s}, 2.094 \mathrm{~m} / \mathrm{s}$, and $3.141 \mathrm{~m} / \mathrm{s})$, applied weight $(40 \mathrm{~N}, 50 \mathrm{~N}$, and $60 \mathrm{~N})$, and sliding distance $(1500 \mathrm{~m}, 3000 \mathrm{~m}$, and $4500 \mathrm{~m})$. ANOVA was used to determine the impact of the test constraints on the wear rate throughout the run. A multiple linear regression formula was established. The dry sliding wear resistance was investigated utilizing the 'smaller is better' criteria. In this study, the normal load has the maximum impact (71.02\%), followed by sliding velocity $(28.13 \%)$ and sliding distance $(1.14 \%)$. The optimal functioning settings found after analysis, include a $40 \mathrm{~N}$ applied weight, a $1500 \mathrm{rpm}$ sliding velocity, and a $1500 \mathrm{~m}$ sliding distance. This was also confirmed by SEM analysis. Lastly, validation tests were performed to double-check the experiment's results. The difference between calculated and actual values was discovered to be less than $10 \%$ which is in agreement with the methodology followed.

\section{Introduction}

Brake pads have three different types of components: metals, ceramics, and polymers making them one of the most complicated composite materials ever manufactured. Finding the right composition and mixing is difficult due to the chemical diversity [1]. The composition and microstructure of the friction materials are significantly responsible for the brake's performance. Brake pads often contain fibers, metallic chips, ceramic particles, minerals, solid elastomers, and lubricants, bonded together by phenolic resins. It should retain a moderate, constant, and dependable coefficient of friction across a wide-ranging variety of temperature, humidity, and braking conditions. By varying the type, shape, and hardness of metals such as copper, steel, and brass, frictional properties and wear of friction materials can be influenced. Brake pads are crucial for braking systems in vehicles. For controlling the speed of disc rotors, the brake pad consists of a backing plate with friction material. Brake pads dissipate a vehicle's kinetic energy to thermal energy through friction [2]. Depending on the vehicle's intended purpose, many different brake pads materials can be used, such as - Semi-metallic, ceramic, organic, etc. [3]. When choosing a brake pad material, there are many factors to consider. Modern brake pads should have a friction coefficient that is low enough to prevent wheel locking yet high enough to give enough stopping power [4]-[6]. For brake pad materials, friction coefficients are usually between 0.3 and 0.5 [7]-[9]. The brake should withstand frictional wear, but not to the point where rotor wear develops faster than brake material is sacrificed. In these circumstances, evaluating different contributing factors in brake pad performance becomes of tremendous importance [10], [11].

As demonstrated in Fig. 1, a large proportion of brake debris will be discharged as airborne particulate matter (PM) over the brake's lifetime cycle. This could be up to $35 \%$. Here, sample losses are not taken 
into account, which would raise the airborne proportion to over $64 \%$ if they were included in the analysis [12]. Subjected to the intensity of the braking, 50-90\% of the worn debris was in the form of airborne particles, according to extensive laboratory tests [13].

Due to their higher reactivity with increased surface area to the tissues and biomolecules, the impact of these nanoparticles on the human body was investigated. It was discovered that these can simply pass into the respiratory duct, causing risks linked to oxidative stress [14]. Nanoparticles have been found to penetrate the bloodstream and go to other organs such as the liver, kidneys, and brain in several investigations. Furthermore, because of their size, these atoms have a slow sedimentation rate. The particles can travel thousands of kilometers from their source when dispersed into the air. The particles having a diameter of fewer than 2.5 microns (PM2.5) can penetrate the lungs' narrow air ducts. This is a matter of attention as these can irritate the eyes, nose, and lungs, leading to weakened lungs and chronic bronchitis. Nanoparticles are absorbed into the body through the lungs, skin, and digestive system. Afterward, it can pass into the bloodstream, due to its small size. Nanoparticles are more reactive and harmful due to their large surface area, leading to pulmonary inflammation, oxidative stress, and cardiac ailments [15-17].

Future environmental and health studies will have a significant barrier in analyzing and assessing wear debris from brake pad-disc systems [18]. This research work is motivated by the realization of hazardous wear debris generated during the braking process, which must be checked and characterized to reduce the fatal impact on the ecosystem, environment, and health, as well as to improve the braking efficiency of semi-metallic friction materials by optimizing the process parameters of friction testing of brake materials in sliding (pin-on-disc test).

For this reason, Taguchi's experimental design, combined with ANOVA analysis, is a robust instrument for examining the influence of various parameters on brake performance [19]. Multiple studies have been conducted to improve the manufacturing process of brakes on the above designs [20]. But there are few studies on the implementation of Taguchi and Anova analysis to optimize operating parameters for semimetallic brake pads. To establish critical parameters impacting wear rate, a study on variance (ANOVA) tests is conducted. Through a series of studies, the Taguchi technique was previously used to optimize the wear attributes of different compositions. When used with ANOVA, the Taguchi approach can lead to the highest level of design optimization [21]-[26].

\section{Experimental Design}

\subsection{Process parameter selection}

Three process parameters were chosen to be adjusted in this study in order to maximize wear control efficiency.

\subsubsection{Load}


The stationary pin was hard-pressed against the spinning disc by the normal load. The pin's wear is almost usually proportional to the load it is subjected to (based on Archard Eqn). When the normal load increases, frictional heat is created at the contact surface, resulting in a loss of material strength. The weight and the sliding speed have an impact on the amount of friction force. The wear rate increases substantially as the load is increased. However, the load and the sliding speed combination behavior have an impact on the quantity of friction force. When paired with higher sliding speed, loading, and sliding over long distances, small coefficients of friction reduce wear [27].

\subsubsection{Sliding distance}

By multiplying the linear speed by the test duration, the sliding distance is calculated. The wear rate will rise as the sliding distance increases. The profile roughness, interface behavior, and real contact zone among other things, alter as the sliding distance rises, leading to a differential in wear rate with sliding distance. Wear is associated with asperity interaction [28-30]. It is provided by:

Sliding distance in metres, $x=\Pi$. d. N. $t(1)$

where $\mathrm{d}=$ wear track diameter in metres; $\mathrm{N}=$ disc speed in RPM; $\mathrm{t}=$ run time in mins.

\subsubsection{Sliding velocity}

The pin and revolving disc's relative velocity is proportional to the disc's rotation speed multiplied by the pin's distance (radius) from the rotation axis. Regardless of the ambient temperature, an increase in sliding velocity causes a temperature increase at the siding interface $[29,30]$. It is given by:

Sliding velocity in $\mathrm{m} / \mathrm{s}, \mathrm{v}=\frac{\Pi \cdot D \cdot N}{60}(2)$

$D=$ Diameter of the disc in meters.

$\mathrm{N}=$ revolution per $\min$.

Table 1 lists the specified control factors as well as their corresponding levels.

Table 1

Selected control factors and respective levels

\begin{tabular}{|llll|}
\hline Level & Factors & & \\
\cline { 2 - 4 } & Load $(\mathrm{N})$ & Sliding distance $(\mathrm{m})$ & Sliding velocity $(\mathrm{m} / \mathbf{s})$ \\
\hline 1. & 40 & 1500 & 1.047 \\
\hline 2. & 50 & 3000 & 2.094 \\
\hline 3. & 60 & 4500 & 3.141 \\
\hline
\end{tabular}

\subsection{SN Ratio and design of experiments}


Experiment design is the most critical and robust technique for simultaneously analyzing the interaction of multiple constraints. It entails the step-by-step process that must be performed in a specific order to optimize the result. To analyze the effect of different experiment variables, an evaluation of primary factors and corresponding factors needs to be done. The experimental design is divided into three stages: plan, experimentation, and investigation. Identifying the mix of elements and levels that will produce the needed information, is a critical phase in the DOE process [31,32]. The Taguchi approach entails using a robust design of tests to reduce variation in a process. It also analyses interactions among the constraints. It results in a method for determining optimal process parameters that is efficient, simple, and systematic. The technique considerably decreases the required tests to predict the reaction parameters when equated to conventional experimentation. The Taguchi method employs typical orthogonal arrays to produce the engineering optimization and analysis experiment plan. The experiment data are then studied with (ANOVA) [33,34]. The goal of the tests was to see how different operating circumstances affected brake pad wear. The Taguchi method was used to evaluate the loss function. This methodology reduced the number of experiments and uncontrollable components' influence, thus saving time and production costs. It also led to a simplified and precise process. Taguchi chose the signal-to-noise, (SN) ratio as the value criterion of performance as shown in Table 2. The ratio assesses how the response swings regarding the nominal or goal value under various noise conditions. It is calculated as:

Table 2

SN Ratio and their meaning

\begin{tabular}{|lll|}
\hline S/N Ratio & Objective & Meaning \\
\hline $\mathrm{S} / \mathrm{N}=-10 \log \frac{1}{n}\left(\Sigma \mathrm{y}^{2}\right)$ & Higher is better & Response maximization \\
\cline { 2 - 3 } & Nominal is the best & Shifts mean to a target value \\
\cline { 2 - 3 } & Smaller is better & Response minimization \\
\hline
\end{tabular}

$\mathrm{SN}=-10 \log \frac{1}{n}\left(\Sigma \mathrm{y}^{2}\right)(3)$

The orthogonal array was used to categorize the optimal arrangement of test constraints. The dependent variables are adjusted to modify the noise. External inputs that affect the formulation process are difficult to manage with these noise components. These include the sliding velocity, sliding distance, and normal load. The purpose of optimizing the formulation process is thus to identify and then employ the optimum control factor values.

The $(\mathrm{S} / \mathrm{N})$ ratio can be obtained from the data, as well as the necessary control variables for minimizing noise. The ratios for each control parameter were determined in this study to lower the wear rate. In Table 2, ' $n$ ' stands for the number of observations, whereas ' $y$ ' stands for the data. $\mathrm{N}$ denotes the noise and $\mathrm{S}$ denotes the signal. According to the experimental objectives, there are various conditions of $\mathrm{SN}$ ratios, as shown in Table 2, e.g. 'larger is better' etc. The SN ratio was established to attain the objective of 'the smaller the better' because the goal of this study is to reduce wear. The outcomes were utilized to 
obtain a response (wear) as a result of modifying a process parameter. The wear rate is a performance criterion in this situation, and the lower the output, the better. The experimental design is shown in Table 3.

Table 3

An orthogonal array of variables for process optimization.

\begin{tabular}{|llll|}
\hline S.No. & Load & Sliding Distance & Sliding Velocity \\
\hline 1 & 40 & 1500 & 1.047 \\
2 & 40 & 3000 & 2.094 \\
3 & 40 & 4500 & 3.141 \\
4 & 50 & 1500 & 2.094 \\
5 & 50 & 3000 & 3.141 \\
6 & 50 & 4500 & 1.047 \\
7 & 60 & 1500 & 3.141 \\
8 & 60 & 3000 & 1.047 \\
9 & 60 & 4500 & 2.094 \\
\hline
\end{tabular}

\subsection{Plan Of Experiment}

The experiment contained three main factors, and three corresponding sub-levels were designed employing the Taguchi experiment methodology (see Fig. 2.). Three parameters were adjusted for a dry sliding wear test for three levels; sliding velocity, sliding distance, and normal load. Table 3 shows the values of the three restrictions chosen for the trial. The Taguchi model's run order was used in a series of tests. The wear rate is the model's response. The first column represents normal load, the second column depicts the sliding distance, and the last column shows the sliding velocity. The remaining columns describe the interactions in an orthogonal L9 array. The wear rate was the response variable that needed to be looked into. The form of output being researched determines the $(\mathrm{S} / \mathrm{N})$ ratio, which summarizes the many data combinations of the run. The "smaller is better" features were set to explore the dry sliding wear.

\section{Experimental Procedure}

\subsection{Materials}

The performance of commercial semi-metallic brake-pad friction materials was researched. Pin samples of brake-pad friction material were made from semi-metallic brake pads according to ASTM G99 test 
requirements with dimensions of $8 \times 8 \mathrm{~mm}$ base with $15 \mathrm{~mm}$ height, as illustrated in Fig. 3(a). As depicted in Fig. 3, (b) a grey cast-iron rotor with $50 \mathrm{~mm}$ diameter and a $6 \mathrm{~mm}$ thickness was utilized as a counter disc. A pin-on-disc tribometer using a spinning rotor and a counter-weight was used to apply the requisite normal pin surface pressure (see Fig. 4). The pin surface is made flat to maximize contact with the spinning disc to begin the test. Dry sliding experiments were carried out at varying sliding distances of 1500,3000 , and 4500 meters with a sliding velocity of 500,1000 , and $1500 \mathrm{rpm}$, nominal contact load of 40,50 , and $60 \mathrm{~N}$, and track radius of $20 \mathrm{~mm}$. LVDT coupled with a strain gauge is attached at the contact to automatically monitor the frictional force and displacement in the tribometer. The device was connected to computer 'Magview' software to measure and screen the variation in sliding velocity, frictional force, and wear with time. The wear was continuously monitored and recorded using software throughout the test.

Table 4 shows the major semi-metallic brake-pad composition as determined by the XRF experiment. It also shows the shift in brake pad makers towards copper-free pads as there is a trace amount of copper in the composition.

Table 4

Brake-pad

composition as examined by XRF.

\begin{tabular}{|ll|}
\hline Element & Wt. (\%) \\
\hline $\mathrm{Si}$ & 0.187 \\
$\mathrm{P}$ & 1.827 \\
$\mathrm{~S}$ & 1.013 \\
$\mathrm{Ca}$ & 1.229 \\
$\mathrm{Mn}$ & 0.448 \\
$\mathrm{Cr}$ & 0.258 \\
$\mathrm{Ti}$ & 0.133 \\
$\mathrm{Fe}$ & 88.063 \\
$\mathrm{Cu}$ & 0.089 \\
\hline $\mathrm{Ni}$ & 0.065 \\
\hline $\mathrm{Zn}$ & 0.276 \\
\hline $\mathrm{Ba}$ & 3.140 \\
\hline
\end{tabular}

The surface of the virgin brake pin before performing the tribo-test is depicted in Fig. 5a with EDX analysis and spectrum in $5 \mathrm{~b}$ respectively. It can be seen that carbon is the prominent element present here along with iron. Figure 5a. represents the microstructure of the top surface of the virgin brake-pad 
sample. The spectrum $5 \mathrm{~b}$. shows the presence of $\mathrm{Fe}, \mathrm{C}, \mathrm{Mn}$, and $\mathrm{Ni}$ elements present in the microstructure.

\subsection{Wear Test Setup}

A computerized Pin-on-disc tribometer was employed to conduct dry sliding wear trials at room temperature and humidity. (Model: Magnum, India). The investigation was executed equivalently with ASTM G99-04 guidelines. To quantify the wear rate, the weight difference between the wear sample before and after the test must be calculated using calibrated weighing equipment. A digital electronic balance with precision up to four decimal values was used to determine the initial and final weight of the pin. Rectangular pins were machined from the commercial semi-metallic brake pad. Before testing, the disc and pin surfaces are abrased with 300 grit emery paper. A rectangular sample pin with $8 \mathrm{~mm}$ sides and $15 \mathrm{~mm}$ height was held against a rotating grey cast iron disc, and a standard load was applied using a lever attached to the tribometer. A grey cast iron rotor with a $350 \mathrm{HV}_{60}$ hardness was used as a counterface material. The disc had an initial roughness of $0.18 \mu$. The weight variation due to sliding wear is calculated by subtracting the starting weight of the pin from the final weight. The wear volume was calculated using the matched density data. The wear rate of semi-metallic pins is given by the ratio of the pin's volume loss to sliding distance. The formula is given as.

$\mathrm{Q}=$ wear rate $\left(\mathrm{mm}^{3} / \mathrm{m}\right)=$ wear volume loss $/$ sliding distance $=w=\frac{V_{f}-V_{i}}{l}=\frac{W_{f}-W_{i}}{\rho l}$ (4)

where $w_{f}=$ Final weight of pin in $g, w_{i}=$ Initial weight of the pin in $g, \rho=$ density of pin in $\mathrm{g} / \mathrm{mm}^{3}, I=$ sliding distances in metres.

\subsection{Characterization Techniques}

The test specimens' worn surfaces were examined employing an SEM (scanning electron microscope) to confirm the wear process. The ED-XRF (Model: Epsilon-1) device is utilized to detect and quantify constituents in the semi-metallic brake pad. The standard library and calibration curves are employed to compare the sample's characteristic X-ray fluorescence radiation.

FESEM, FEl manufactured (Apreo LoVac model) SEM examination was performed at $500 \mathrm{~nm}$ for virgin brake pin surface and 5 microns for wear brake pin surface. In the Leica Ultra Microtome EM UC7, samples were sputtered with gold nanoparticles at a thickness of $10 \mathrm{~nm}$ before SEM examination (Sputter Coater) to avoid charging.

\section{Results And Discussion}

\subsection{Signal to noise (SN) analysis of wear behavior}


The study aimed to discover the critical components controlling the wear process while operating to keep the wear rate as low as feasible. Table 5 illustrates the $\mathrm{S} / \mathrm{N}$ ratio findings for various parameter combinations using an orthogonal array. MINITAB 18 converted the test data into ratios to measure the superiority attributes.

Table 5

An orthogonal array of process variables for semi-metallic brake pad.

\begin{tabular}{|llllll|}
\hline S.No. & $\begin{array}{l}\text { Load } \\
(\mathbf{N})\end{array}$ & $\begin{array}{l}\text { Sliding Distance } \\
(\mathbf{m})\end{array}$ & $\begin{array}{l}\text { Sliding Velocity } \\
(\mathrm{m} / \mathbf{s})\end{array}$ & Wear Rate & $\begin{array}{l}\text { S/N Ratio Wear } \\
\text { Rate }\end{array}$ \\
\hline 1 & 40 & 1500 & 1.047 & 0.00023814 & 72.4633 \\
2 & 40 & 3000 & 2.094 & 0.00017933 & 74.9269 \\
3 & 40 & 4500 & 3.141 & 0.00013671 & 77.2839 \\
4 & 50 & 1500 & 2.094 & 0.00031752 & 69.9645 \\
5 & 50 & 3000 & 3.141 & 0.00023152 & 72.7080 \\
6 & 50 & 4500 & 1.047 & 0.00054243 & 65.3130 \\
7 & 60 & 1500 & 3.141 & 0.00038367 & 68.3208 \\
8 & 60 & 3000 & 1.047 & 0.00091288 & 60.7917 \\
9 & 60 & 4500 & 2.094 & 0.00061746 & 64.1877 \\
\hline
\end{tabular}

Wear has been studied in relation to control test constraints such as sliding distance, load, and sliding velocity. Tables 6 and 7 show the ordering of test constraints based on SN ratios obtained for constraints.

Table 6

Responses for mean wear.

\begin{tabular}{|llll|}
\hline Level & Load & Sliding Distance & Sliding Velocity \\
\hline 1 & 0.00018473 & 0.00031311 & 0.00056449 \\
\hline 2 & 0.00036383 & 0.00044124 & 0.00033437 \\
\hline 3 & 0.00060094 & 0.00039514 & 0.00025063 \\
\hline Delta $(\Delta)$ & 0.00041622 & 0.00012813 & 0.00031385 \\
\hline Rank & 1 & 3 & 2 \\
\hline
\end{tabular}


Table 7

Response for SN ratio for wear.

\begin{tabular}{|llll|}
\hline Level & Load & Sliding Distance & Sliding Velocity \\
\hline 1 & 74.89143 & 70.24956 & 66.18937 \\
\hline 2 & 69.32861 & 69.47563 & 70.26794 \\
\hline 3 & 65.00826 & 69.50311 & 72.77099 \\
\hline Delta $(\Delta)$ & 9.88317 & 0.77393 & 6.58162 \\
\hline Rank & 1 & 3 & 2 \\
\hline
\end{tabular}

The controlling parameters are statistically crucial in $\mathrm{SN}$ ratio. It is concluded that the most critical factor controlling wear rate in the experiment is applied load, followed by sliding velocity and sliding distance. Figures 6(a), (b), and 7 illustrate the core impact design for mean, the $\mathrm{SN}$ ratio for wear, and interaction effect designs among controlling constraints. The inclination of the main impact plots determines the importance of each component. The most critical parameter is the one where the line has the most remarkable inclination. The principal impact plots for wear in Fig. 6(a) and the S/N ratio in Fig. 6(b) clearly show that the most essential parameter is the applied load.

Nonetheless, the sliding velocity of a parameter has a significant impact. When determining whether or not parameter effects are non-parallel, and interaction plot might be employed. There was only nominal interaction if the lines on an interaction plot aren't parallel; if the lines interact, there was considerable interaction between the parameters. As demonstrated in Fig. 7, the factors load and sliding velocity significantly interact. In contrast, rest has a minor relationship. As a result of this study, it is clear that the normal load has the most significant effect on the semi-metallic brake pad wear characteristics.

The contour image in Figs. 7 and 8 depict the interplay of the various parameters and their impact on the response variable in an intuitive manner. It can be seen from the plot that load dominates the variation in the other two parameters. For the variation of sliding velocity vs. load, the dominance lies in the range of 40-45 N (Fig. 8a). In contrast, the superiority of sliding distance lies in $2400 \mathrm{~m}$ to $4500 \mathrm{~m}$ for the $40-50 \mathrm{~N}$ load as shown in the variation of sliding distance vs. load (Fig. 8b). Both sliding velocity and sliding distance simultaneously can be seen affecting the wear rate (Fig. 8c). The contour plot is an easier way of understanding how the variation of each parameter affects wear rate.

\subsection{Analysis Of Variance (Anova) Of Wear Rate}

An ANOVA test is used to determine whether or not the results of a survey or experiment are significant. It is a collection of statistical models and estimating processes for analyzing the differences between means. It clarifies how the various groups respond, with a null hypothesis for the test stating that the means of the various groups are equal. If the difference between the two populations is statistically significant, then the two populations are unequal (or different). ANOVA was utilized to explore the impact 
of wear constraints, for example, sliding distance, normal load, and sliding velocity, on experimental outcomes. In an ANOVA, the F value is obtained by dividing the variation between sample means by the variation within the samples. In an ANOVA, the higher the F-value, the greater the variation between sample means compared to variation within the samples. The related p-value is lower when the F-value is higher. The $\mathrm{P}$ number represents the likelihood of error, or the chance that a $\mathrm{F}$ value this large may arise by chance rather than due to a known cause. Table 8 depicts the outcome of the ANOVA of the wear rate for three components adjusted at three levels and their relations. It is used to determine which factor controls the other and the relative contributions of each independent constraint. For this study, a 95 percent confidence level was employed. Sources contributing to the performance measures with a ' $P$ ' value less than 0.05 reflected statistically substantial contributors. For the ANOVA analysis, the following equations are used [35]:

Table 8

ANOVA for $\mathrm{S} / \mathrm{N}$ ratios.

\begin{tabular}{|c|c|c|c|c|c|c|}
\hline Source & $\begin{array}{l}\text { DF } \\
\text { (Degree of } \\
\text { freedom) }\end{array}$ & $\begin{array}{l}\text { Seq SS } \\
\text { (Sequential } \\
\text { sums of } \\
\text { squares) }\end{array}$ & $\begin{array}{l}\text { Adj. SS } \\
\text { (adjusted } \\
\text { sum of } \\
\text { squares) }\end{array}$ & $\begin{array}{l}\text { Adj. MS } \\
\text { (Adjusted } \\
\text { mean } \\
\text { squares) }\end{array}$ & $\begin{array}{l}\text { F } \\
\text { (Factor } \\
\text { value) }\end{array}$ & $\begin{array}{l}\text { P } \\
\text { (Probability } \\
\text { value) }\end{array}$ \\
\hline Load & 2 & 164.277 & 164.277 & 82.1383 & 558.47 & 0.002 \\
\hline $\begin{array}{l}\text { Sliding } \\
\text { Distance }\end{array}$ & 2 & 2.644 & 2.644 & 1.3222 & 8.99 & 0.1 \\
\hline $\begin{array}{l}\text { Sliding } \\
\text { Velocity }\end{array}$ & 2 & 65.065 & 65.065 & 32.5327 & 221.2 & 0.005 \\
\hline $\begin{array}{l}\text { Residual } \\
\text { Error }\end{array}$ & 2 & 0.294 & 0.294 & 0.1471 & & \\
\hline Total & 8 & 231.281 & & & & \\
\hline
\end{tabular}

$$
S Q_{T}=S S_{L}+S S_{D}+S S_{V}
$$

5

$\{S Q\}_{-}\{T\}=\{\text { varSigma }\}_{-}\{1\}^{\wedge}\{n\}\{d\}_{-}\{i\}^{\wedge}\{2\}-\{R\}^{\wedge}\{2\} / n$

6

$\{S S\}_{-}\{\mid\}=\{\text {varSigma }\}_{-}\{i=1\}^{\wedge}\{t\}\left(\{S d\}_{-}\left\{i^{\wedge}\{2\} / t\right)-\{R\}^{\wedge}\{2\} / n\right.$

7

where $\mathrm{SQ}_{\mathrm{T}}$ is the net-sum of squares, $\mathrm{SS}_{\mathrm{L}}$ is the load-sum of squares, $\mathrm{SS}_{\mathrm{D}}$ is the sliding distance-sum of squares, $\mathrm{SS}_{\mathrm{V}}$ is the sliding velocity sum of squares, $\mathrm{n}$ is the number of data, $\mathrm{Sd}_{\mathrm{i}}{ }^{2}$ is the sum of the experiments relating constraint $\mathrm{I}$ at level $\mathrm{i}$ and $\mathrm{R}$ are the resultant for all the experiments.

It can be seen that for semi-metallic brake pads, the load has the supreme effect on the wear rate. As a result, during the wear process, the load is a critical control component to consider, followed by sliding 
velocity and sliding distance. The interaction terms have a minor effect on the wear rate.

\section{Multiple Linear Regression Model}

The statistical program tool 'MINITAB-18' is employed to obtain a multiple linear regression setup, which establishes a link between an independent parameter and a response by associating experimental values with an equation. In the resulting regression equation, the ANOVA-derived significant factors, namely the applied sliding velocity, sliding velocity, and load are linked. The model of multiple linear regression for given $\mathrm{n}$ data [36]:

$y=\beta_{\square}+\beta_{1} x_{1}+\ldots .+\beta_{n} x_{n}+\square(8)$

' $y$ ' = forecasted value of dependent variable, ' $\beta_{0}^{\prime}=y$ intercept, ' $x$ ' = independent variable, ' $n$ ' = number of independent variable and ' $\mathrm{Q}$ ' = error

Least estimator is derived by:

$\{\backslash \text { beta }\}_{-}\{1\}=\backslash$ varSigma $(\mathrm{xi}-\backslash$ stackrel \{\}$\{\mathrm{x}\})(\mathrm{yi}-\backslash$ stackrel $\{-\}\{\mathrm{y}\}) / \backslash$ varSigma $\{(\mathrm{xi}-\backslash \text { stackrel }\{-\}\{\mathrm{x}\})\}^{\wedge}\{2\}$ 9

When the parameters of a model are linear, it is said to be linear. So, \partial \text\{y\}/ partial $\{\backslash$ beta \}text $\{i\}$ should not depend on any $\beta$.

The following is the wear rate regression equation for the of semi-metallic brake pad:

Wear rate $\left(\{\mathrm{mm}\}^{\wedge}\{3\} / \mathrm{m}\right)=-0.00044926+\backslash$ left$($ Load $\backslash$ left[N\right] $\backslash$ right $)$. left $(1.86 \mathrm{E}-0.5 \backslash$ right $)+\backslash$ left(Sliding distance $\backslash$ left[m\right] $\backslash$ right). $\backslash$ left(3.97E-0.8\right) - $\backslash$ left(Sliding velocity $\backslash$ left $[\backslash$ frac $\{m\}$

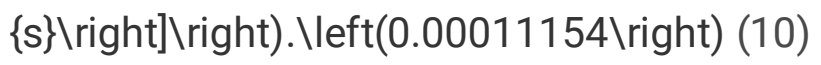

Eq. (10) shows that normal load has a considerable impact on wear rate, strongly influenced by load, followed by sliding velocity.

\section{Validation Test}

The final phase in the experiment design procedure is the validation examination. After reaching the optimum level for a process parameter, a verification test is necessary to examine the correctness of the trials. Dry sliding tests were done using a pre-set set of constraints to authenticate the statistical investigation, as indicated in Table 9. Table 10 shows the test results, which were deemed to be confirmatory with an error of less than $10 \%$. The wear rate for confirmation tests is depicted in Fig. 9 as a bar graph. 
Table 9

Confirmatory test table.

\begin{tabular}{|llll|}
\hline Experiment No. & Load & Sliding Distance & Sliding Velocity \\
\hline 1 & 40 & 3000 & 1.047 \\
\hline 2 & 40 & 1500 & 3.141 \\
\hline
\end{tabular}

Table 10

Confirmation test for wear rate.

\begin{tabular}{|llll|}
\hline Experiment No. & Experimental Wear Rate & Predicted Wear Rate & \% Error \\
\hline 1 & 0.0002718 & 0.002990 & 9.90 \\
\hline 2 & 0.0001367 & 0.000125 & 8.55 \\
\hline
\end{tabular}

The wear debris formation starts due to relative motion and shear stress. The minimum wear takes place at the optimized condition as found through the analysis. It is also confirmed by SEM image (at $40 \mathrm{~N}$, 1500RPM, 1500m) as depicted in Fig. 10a. The friction plane is an interface between pin and disc. It is formed due to wear particles from both disc and pin and their gradual compaction and sintering. It acts as a third body mechanism, reducing wear rate, which may have led to the optimized wear. Maximized wear debris formation can be seen at extreme operating conditions of 60N,1500RPM,4500m, as depicted in Fig. 10b. The wear process is dynamic in nature. The continuous build-up and break-up of the friction plane can be seen. Abrasive wear is found to dominate. Figure 11 shows the radar chart representing the interaction of the contributing process factors. It is a graphical method of representing multivariate data to show the percentage involvement of the three process parameters. In Fig. 12, the load has the maximum effect followed by the sliding velocity and sliding distance for wear.

\section{Conclusions}

The semi-metallic friction material was examined against grey cast iron rotors under dry sliding conditions, and the Taguchi technique was utilized to categorize the ideal operating settings. Validatory tests were performed to confirm the ideal wear rate. The outcomes of the ANOVA and S/N ratio analysis are as follows:

- The normal load has the most significant impact on wear rate for semi-metallic brake pads, followed by sliding velocity and sliding distance.

- The wear rate at intermediate conditions may be estimated with acceptable accuracy using the regression equation obtained for the semi-metallic brake pad.

- Confirmation of test data revealed an error related to dry sliding wear rate of $9.90 \%$ and $9.78 \%$, respectively. As a result, the regression model for wear rate estimation was successfully verified.

- SEM analysis also confirms the dynamic nature of high wear at $60 \mathrm{~N}, 1500 \mathrm{rpm}, 4500 \mathrm{~m}$, and the optimized wear conditions are found at $40 \mathrm{~N}, 1500 \mathrm{rpm}, 1500 \mathrm{~m}$ through the analysis. 


\section{Declarations}

\section{Acknowledgments}

This bibliographic review has received funding from the Science and Engineering Research Board (SERB) Govt. of India, under the start-up research grant (SRG) scheme with File no. SRG/2021/001174. The authors would like to thank the central library of BITS Pilani-Hyderabad for providing necessary access to different journals.

\section{Author Contributions}

Ashish Saurabh: Visualization, Methodology, Investigation, Validation, Writing an original draft, Data curation. Kartik Joshi: Visualization, Writing an original draft, Methodology. Manoj Abhinav: Investigation, Data curation. Piyush Chandra Verma: Writing-review and editing, Fund acquisition, Conceptualization, Supervision.

\section{Competing Interests}

The authors declare that they have no known competing financial interests.

\section{Data Availability}

The datasets used and/or analysed during the current study available from the corresponding author on reasonable request.

\section{References}

[1] Mikael, E., Begman, F. \& Jacobson S., Surface Characterisation of Brake Pads after Running under Silent and Squealing Conditions. Wear, 232, 163-67 (1999).

[2] Aranganathan, N., \&Jayashree, B., Development of Copper-Free Eco-Friendly Brake-Friction Material Using Novel Ingredients. Wear, 352, 79-91 (2016).

[3] Hendre, K., \&Bachchhav, B., Tribological behaviour of non-asbestos brake pad material. Mater. Today Proc. 38, 2549-2554 (2021).

[4] Straffelini, G., et al. Wear behavior of a low metallic friction material dry sliding against a cast iron disc: Role of the heat-treatment of the disc. Wear, 348-349. 10-16 (2016).

[5] Straffelini, G., Verlinski S., Verma P., C., Valota G., \&Gialanella S., Wear and Contact Temperature Evolution in Pin-on-Disc Tribotesting of Low-Metallic Friction Material Sliding Against Pearlitic Cast Iron. Tribol. Lett., 62, 1-11 (2016). 
[6] Verma, P.,C., et al., Role of the friction layer in the high-temperature pin-on-disc study of a brake material. Wear, 346-347, 56-65 (2016).

[7] Österle, W., Kloß, H., Urban, I. \&Dmitriev, A.,I., Towards a better understanding of brake friction materials. Wear, 263, 1189-1201 (2007).

[8] Sethupathi, P., B., Chandradass, J., \&Saibalaji, M., A., Comparative study of disc brake pads sold in Indian market - Impact on safety and environmental aspects. Environ. Technol. Innov., 21, 101245 (2021).

[9] Tavangar, R., Moghadam, H., A., Khavandi A., \&Banaeifar S., Comparison of dry sliding behavior and wear mechanism of low metallic and copper-free brake pads. Tribol. Int., 151,106416 (2020).

[10] Shi X., et al., Investigation on friction and wear performance of laser cladding Ni-based alloy coating on brake disc. Optik (Stuttg). 242, 167227 (2021).

[11] Alves, C., Evtyugina, M., Vicente, A., Conca, E., \& Amato, F. Organic profiles of brake wear particles. Atmos. Res. 255. 105557 (2021).

[12] Garg, et al., Brake Wear Particulate Matter Emissions. Environmental Science \& Technology. 34, 4463-69 (2000).

[13] Paul, G., et al. Airborne Brake Wear Debris: Size Distributions, Composition, and a Comparison of Dynamometer and Vehicle Tests. Environmental Science \& Technology, 37, 4060-69, (2003).

[14] Günter, et al. Nanotoxicology: An Emerging Discipline Evolving from Studies of Ultrafine Particles. Environmental Health Perspectives. 113, 823-39 (2005).

[15] Andre, et al., Toxic Potential of Materials at the Nanolevel. Science (New York, N. Y.), 311, 622-27 (2006).

[16] Terzano, C., et al., Air Pollution Ultrafine Particles: Toxicity beyond the Lung. European Review for Medical and Pharmacological Sciences, 14, 809-821 (2010).

[17] Buseck, P., R., \& Adachi, K., Nanoparticles in the Atmosphere." Elements, 4, 389-94 (2008).

[18] Schlesinger, R., B., et al., The Health Relevance of Ambient Particulate Matter Characteristics: Coherence of Toxicological and Epidemiological Inferences. Inhalation Toxicology. 18. 95-125 (2006).

[19] Ficici, F., Durat, M., \&Kapsiz M., Optimization of tribological parameters for a brake pad using Taguchi design method. J. Brazilian Soc. Mech. Sci. Eng., 36, 653-659 (2014).

[20] Zaharudin, A., M., Talib, R., J., Berhan, M., N., Budin, S., \&Aziurah M.S., Taguchi method for optimizing the manufacturing parameters of friction materials, Int. J. Mech. Mater. Eng., 7, 83-88 (2012). 
[21] Veličković, S., Stojanović B., Babić, M., \&Bobić, I., Optimization of tribological properties of aluminum hybrid composites using Taguchi design, J. Compos. Mater., 51, 2505-2515 (2017).

[22] Lyu, et al., Recycling of Worn out Brake Pads - Impact on Tribology and Environment. Scientific Reports, 10, 8369 (2020).

[23] Kalhapure, V., A., \&Khairnar H., P., Taguchi method optimization of operating parameters for automotive disc brake pad wear, Appl. Eng. Lett., 6, 47-53 (2021).

[24] Mehboob H., \& Chang, S.,H., Optimal design of a functionally graded biodegradable composite bone plate by using the Taguchi method and finite element analysis. Compos. Struct. 119, 166-173 (2015).

[25] Pattanaik, A., Satpathy, M., P., \& Mishra, S., C., Dry sliding wear behavior of epoxy fly ash composite with Taguchi optimization, Eng. Sci. Technol., 19, 710-716 (2016).

[26] Banker, et al., Wear Behavior in Dry Sliding of Inconel 600 Alloy Using Taguchi Method and Regression Analysis. Procedia Technology, 23, 383-90 (2016).

[27] Riyadh, A., Haftirman, A., \&Rafezi, A., D., Y., Effect of Load and Sliding Speed on Wear and Friction of Aluminum- Silicon Casting Alloy. Int. J. Sci. Res.,2, 3-6 (2012).

[28] Rao, R., N., \& Das, S., Effect of Sliding Distance on the Wear and Friction Behavior of as Cast and Heat-Treated Al-SiCp Composites. Materials \& Design, 32, 3051-58 (2011).

[29] Venkataraman, B., \& Sundararajan, G., The Sliding Wear Behaviour of Al-SiC Particulate CompositesII. The Characterization of Subsurface Deformation and Correlation with Wear Behaviour. ActaMaterialia, 44, 461-73 (1996).

[30] Sannino, A., P., \& Rack. H., J., Tribological Investigation of 2009 Al-20 Vol.\% SiCp/17-4 PH Part I: Composite Performance." Wear, 197, 151-59 (1996).

[31] Taguchi, G., Introduction to quality engineering, Asian Product. Organ. (1990).

[32] Fisher R. A., Design of Experiments, Oliver Boyd, Edinburgh, UK (1951).

[33] Taguchi.G., \&Konishi. S., Taguchi Methods Orthogonal Arrays and Linear Graphs: Tools for Quality Engineering, Am. Supplier Institute (1987).

[34] Taguchi. G., Taguchi on Robust Technology Development: Bringing Quality Engineering Upstream, ASME Press. New York, (1993).

[35] Mustapha, et al., Taguchi and ANOVA Analysis for the Optimization of the Microencapsulation of a Volatile Phase Change Material." Journal of Materials Research and Technology, 11, 667-80 (2021). 
[36] Uyanık, Gülden K., \&Güler, N., A Study on Multiple Linear Regression Analysis. Procedia - Social and Behavioral Sciences, 106, 234-40 (2013).

\section{Figures}
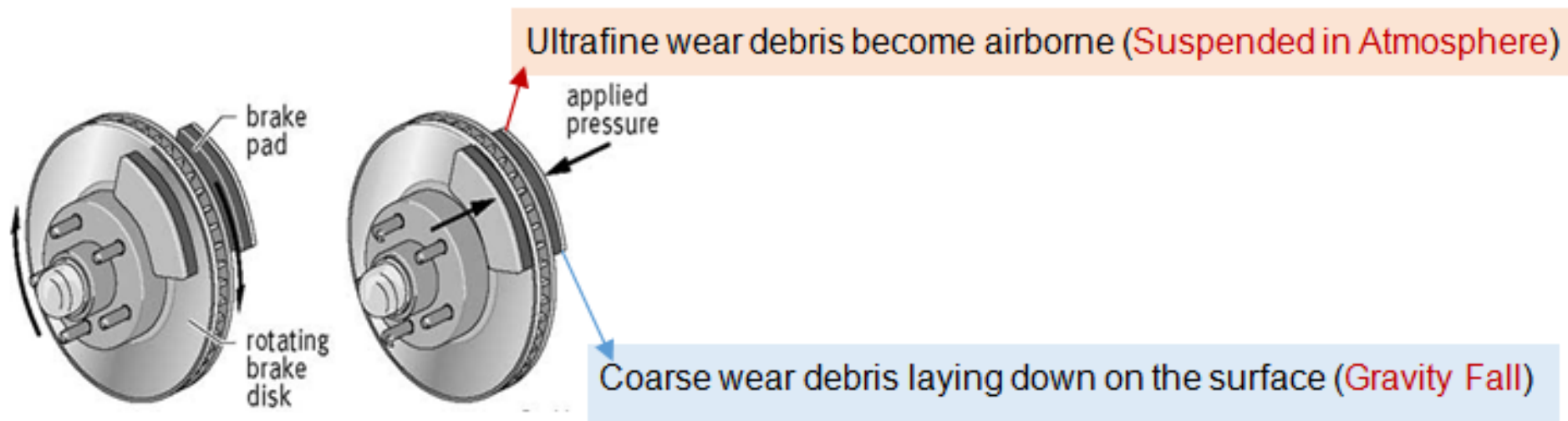

Figure 1

Schematic of the brake-disc system.

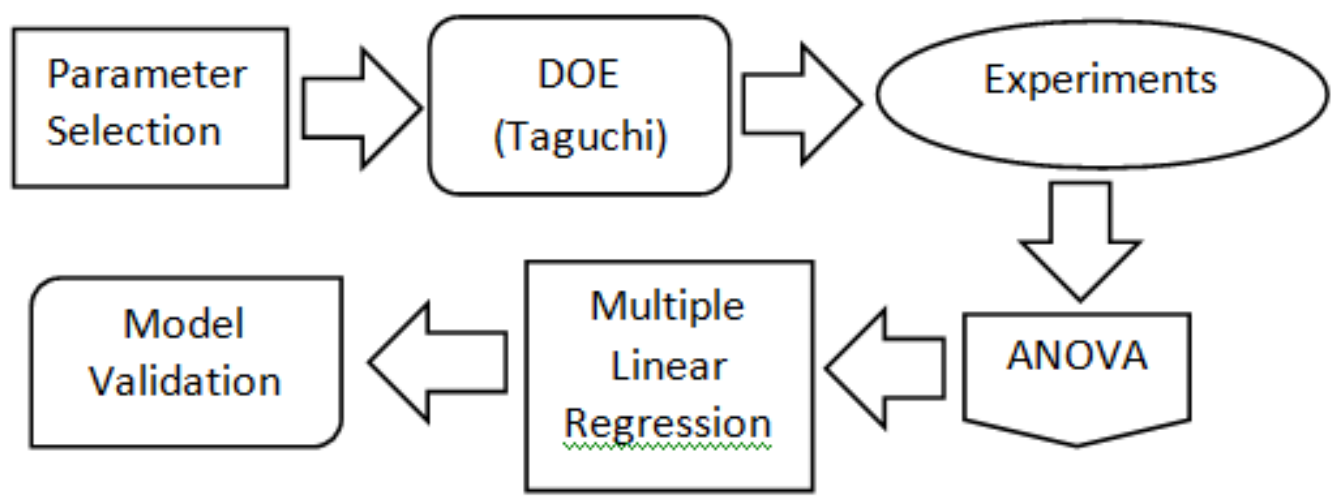

Figure 2

Process flow chart

(a)

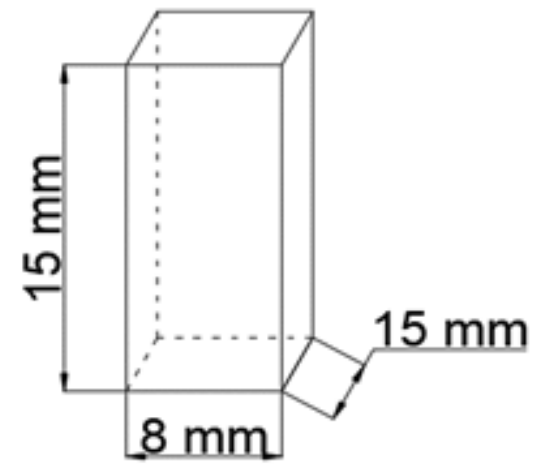

(b)

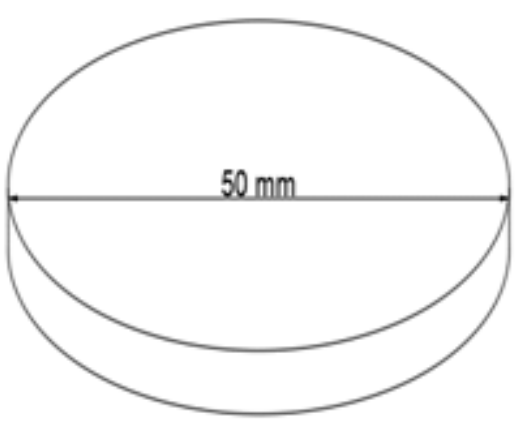


Figure 3

(a) Semi-metallic brake pad pin. (b)cast iron brake rotor with actual dimensions used in the friction test.

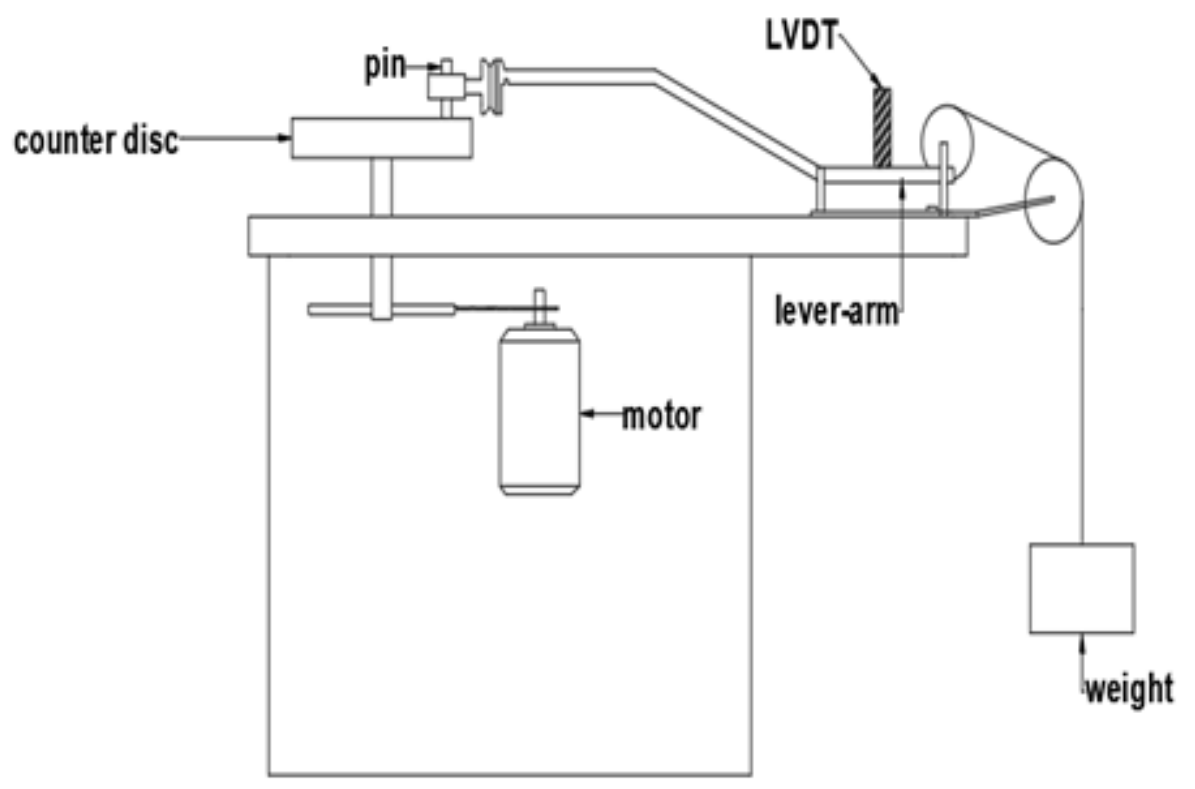

\section{Figure 4}

Pin-on-disctribometer used for friction test.
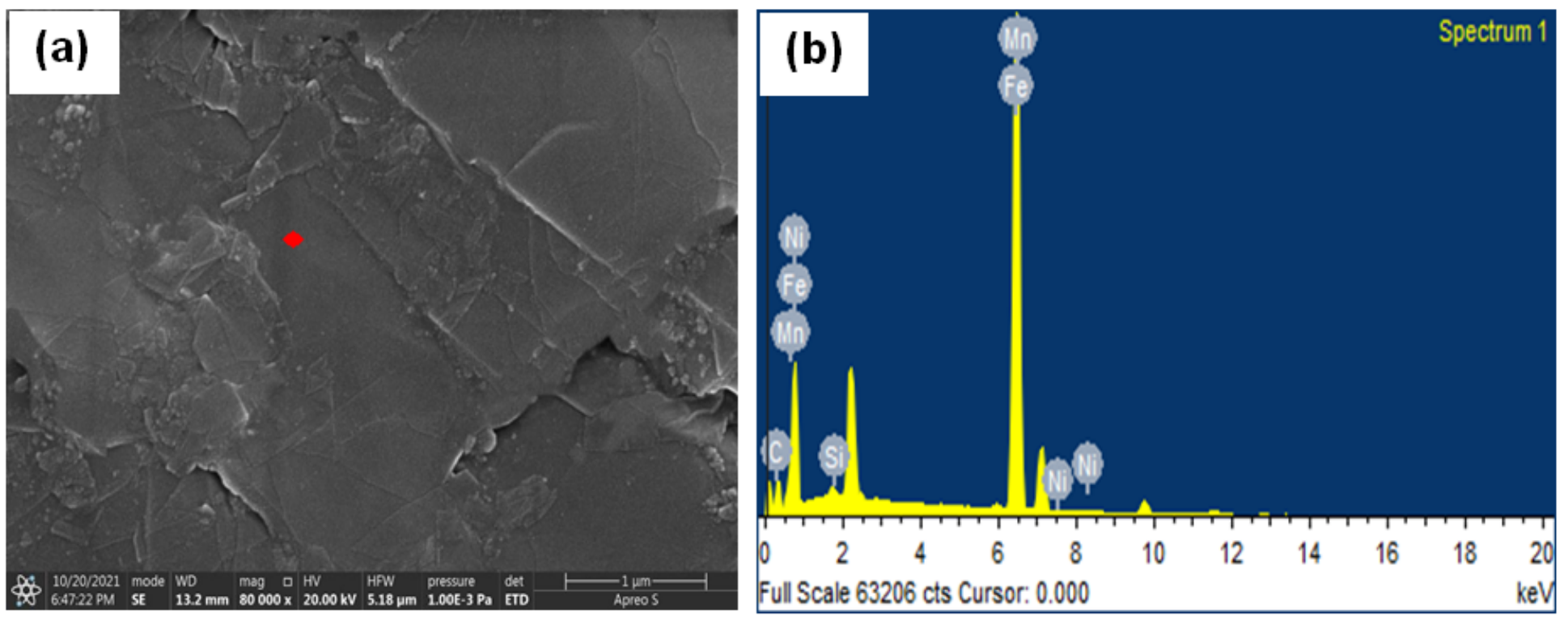

Figure 5

(a) Microstructure of the starting brake-pad material. (b) EDX analysis of the surface of the brake pin (spot shown in red). 

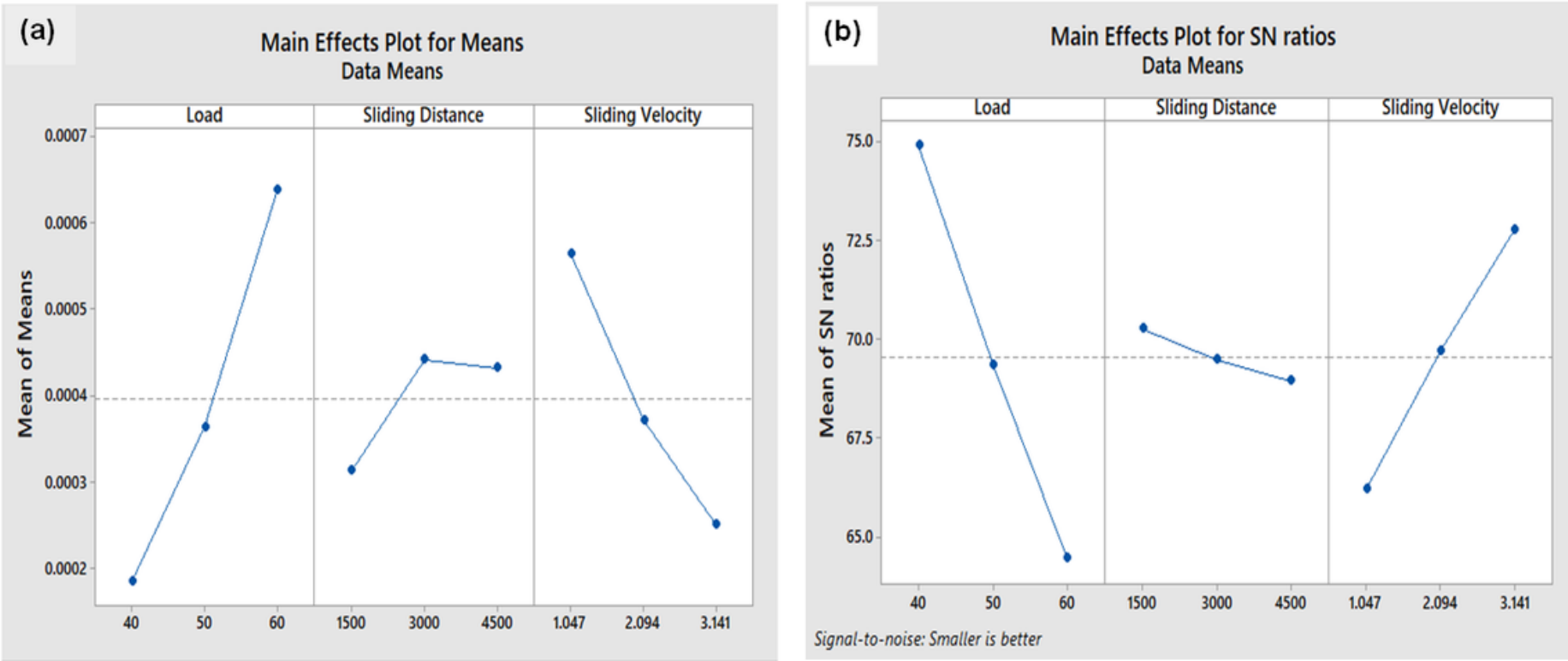

\section{Figure 6}

Main effects plot for (a) Means Wear Rate (b) SN Ratio - Wear Rate

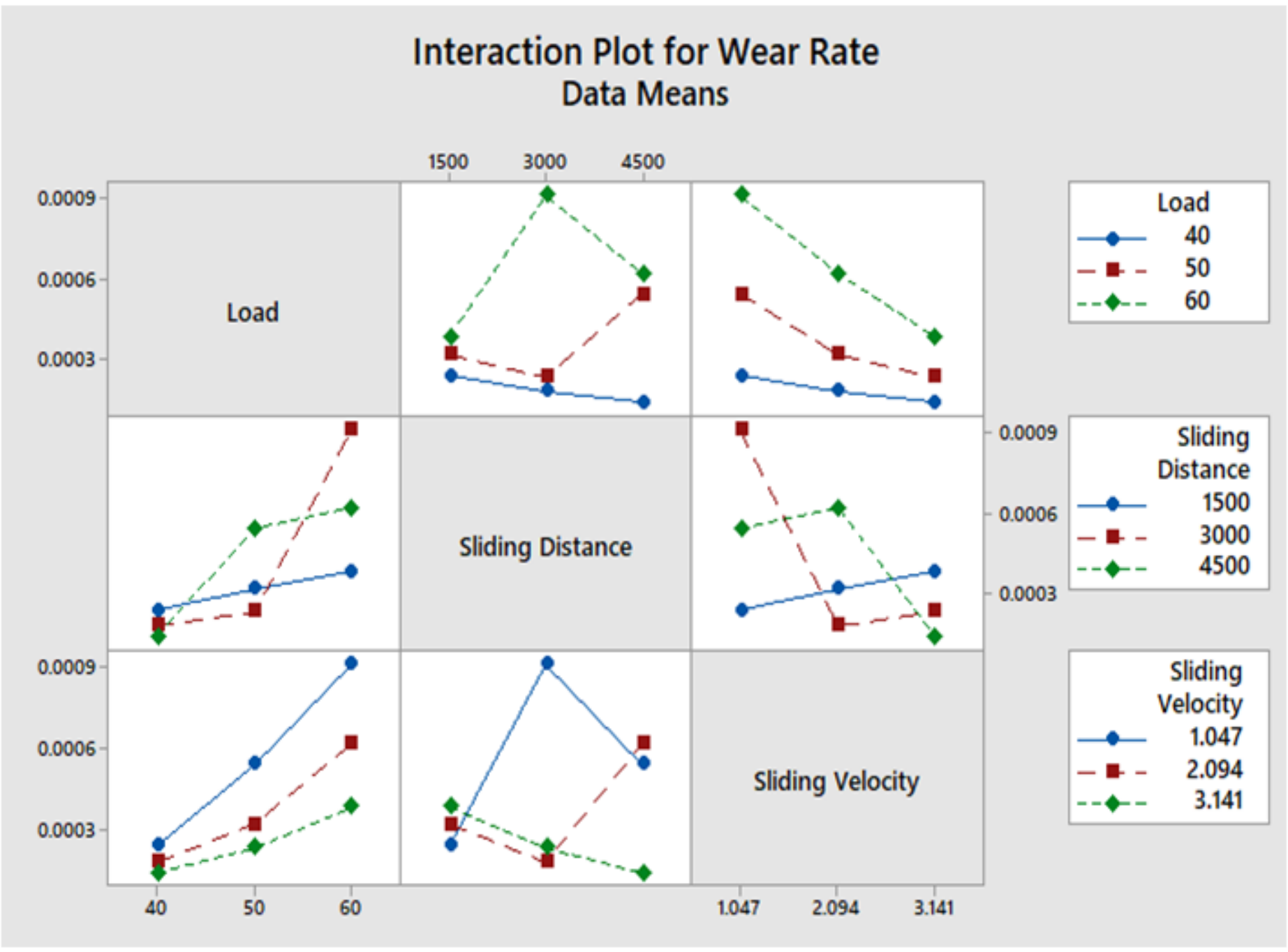


Figure 7

Interaction effect of process parameters on wear rate.
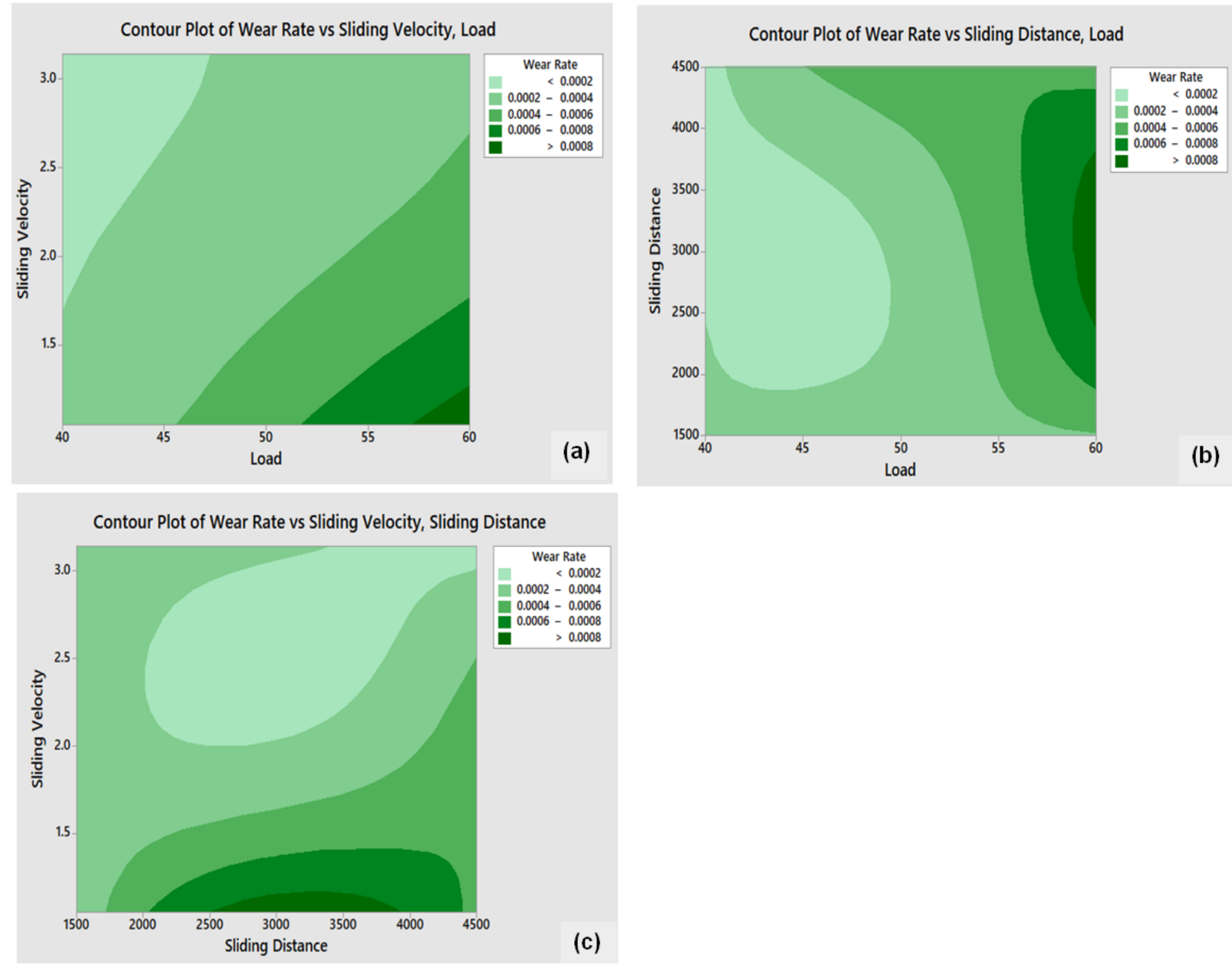

Figure 8

Contour plot of operating parameters. 
0.0035

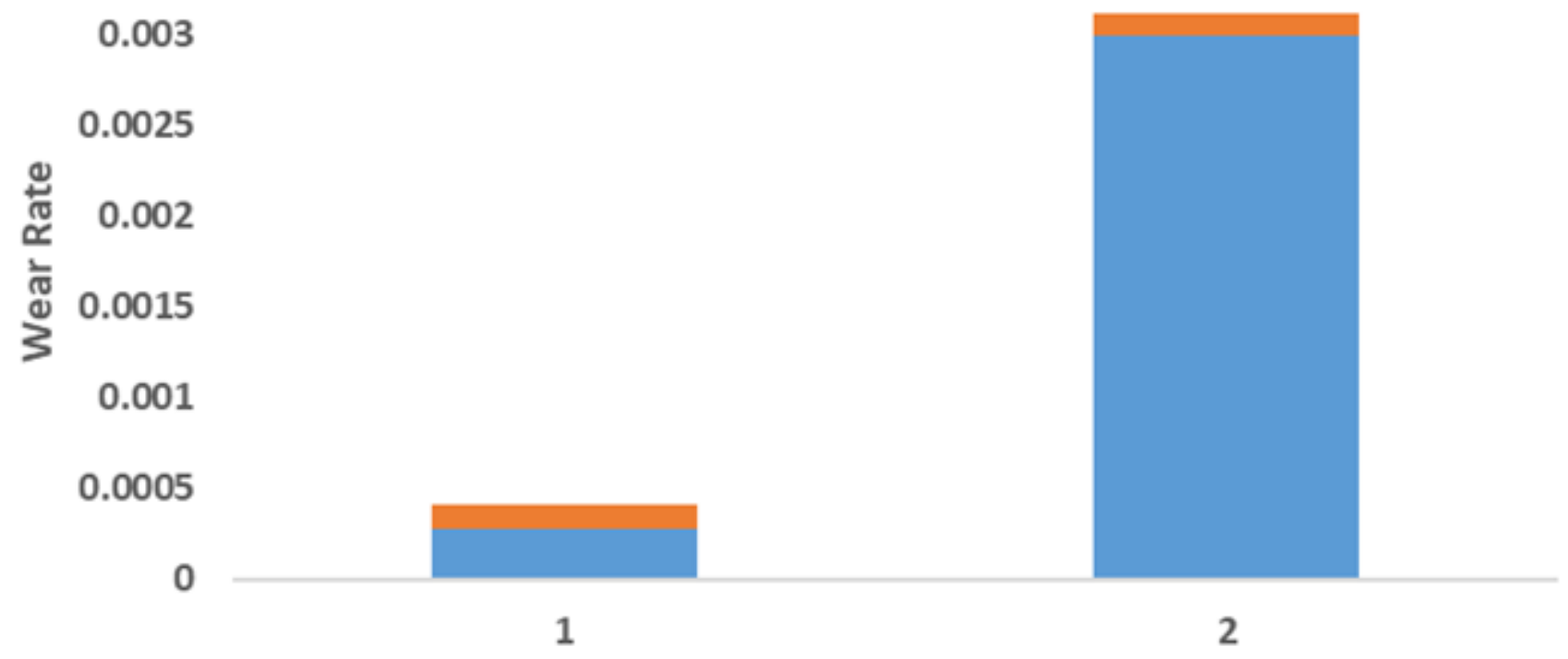

Conformation Test : Experiment Number

घ Predicted Wear Rate $\quad$ Experimental Wear Rate

\section{Figure 9}

Bar graph showing the wear rate for confirmation tests.

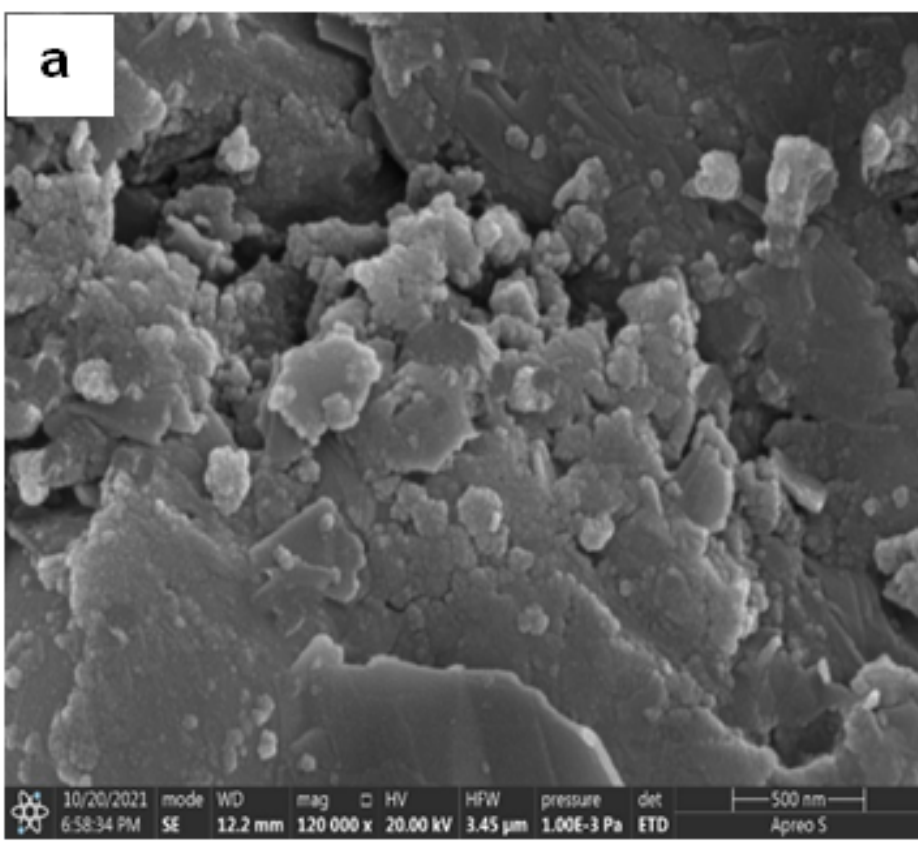

Least wear debris at $40 \mathrm{~N}, 1500 \mathrm{rpm}, 1500 \mathrm{~m}$

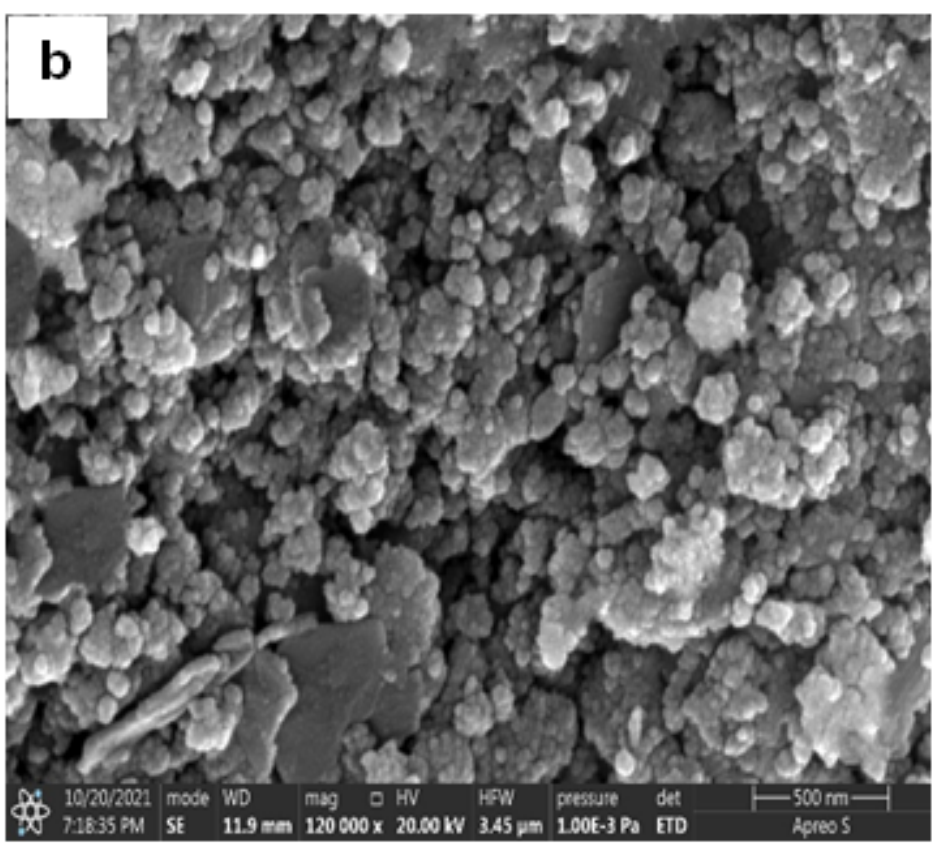

Maximized wear debris at $60 \mathrm{~N}, 1500 \mathrm{rpm}, 4500 \mathrm{~m}$ 
SEM images of worn brake pin surfaces at different operating conditions.

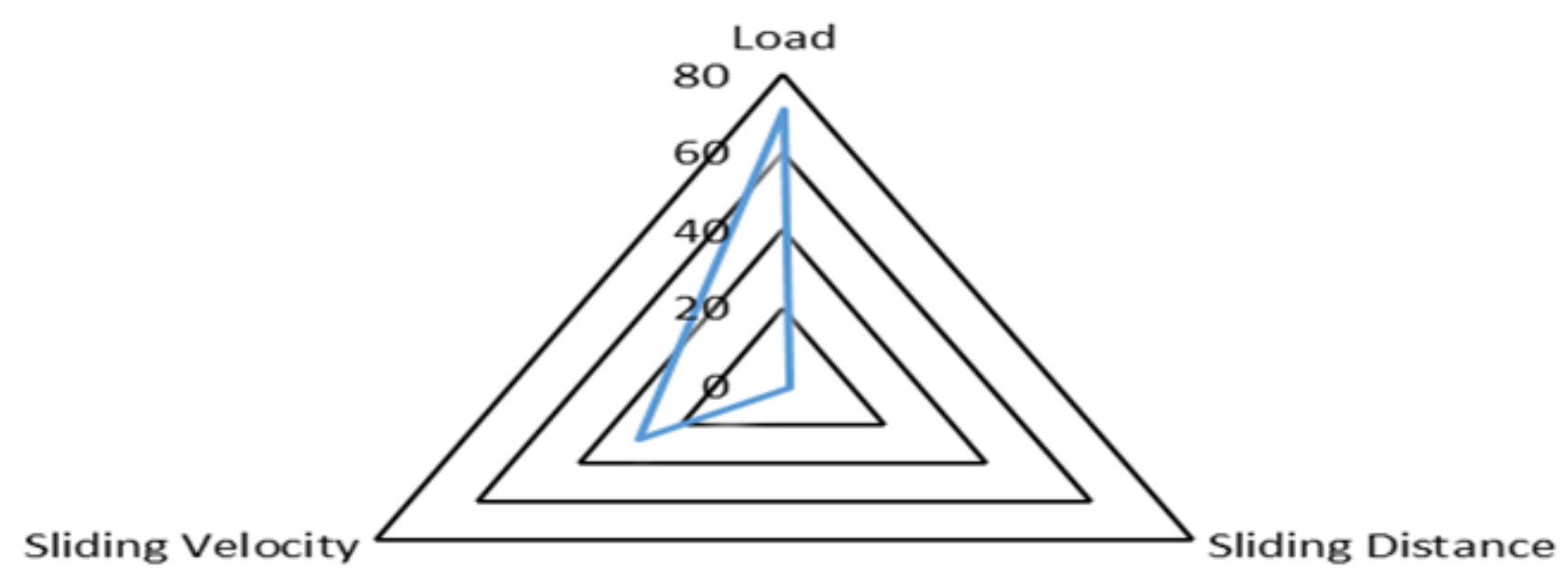

\section{Figure 11}

Radar graph showing the interaction between factors for wear.

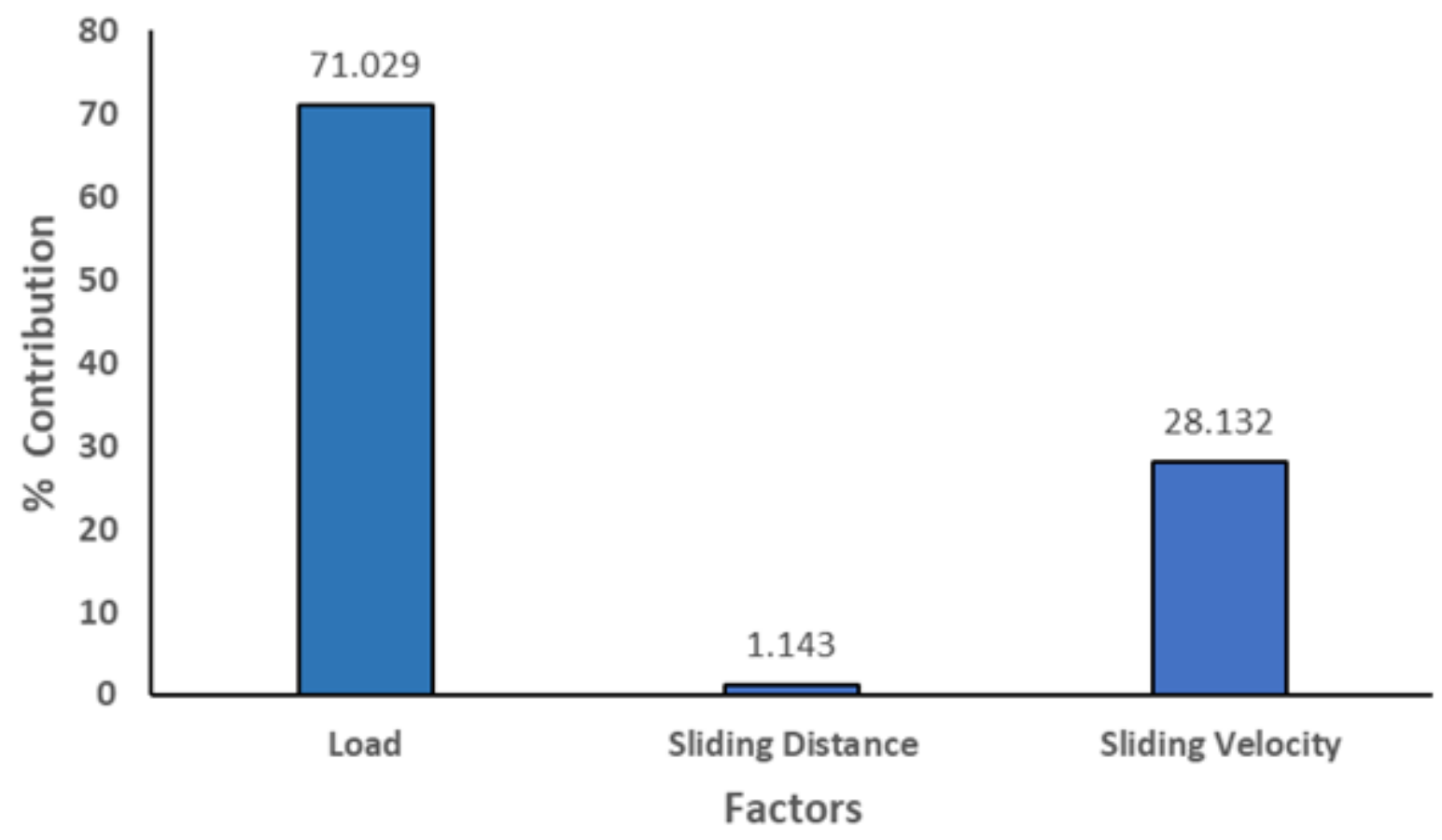

Figure 12

Bar graph representing the contribution of eachprocess factor on wear rate. 